\title{
Assessment of Heavy Metals Pollution of Some Water Resources (Kafr El-Dawar-Egypt)
}

\author{
Abdrabelnabi Mohamed Abdelhady El-Hady*, E. F. Abdelaty, A. E. Boder \\ Department of Natural Resources \& Agricultural Engineering, Agriculture Faculty, Damanhour University, Damanhour, Egypt \\ Email: *emad.fawzy@damanhour.edu.eg
}

How to cite this paper: Abdelhady El-Hady, A.M., Abdelaty, E.F. and Boder, A.E. (2017) Assessment of Heavy Metals Pollution of Some Water Resources (Kafr El-Dawar-Egypt). Natural Resources, 8, 306-319.

https://doi.org/10.4236/nr.2017.84019

Received: October 2, 2016

Accepted: April 27, 2017

Published: April 30, 2017

Copyright $\odot 2017$ by authors and Scientific Research Publishing Inc. This work is licensed under the Creative Commons Attribution International License (CC BY 4.0).

http://creativecommons.org/licenses/by/4.0/

\begin{abstract}
Kafr El-Dawar is a major industrial city and a municipality on the Nile Delta in northern Egypt. Kafr El-Dawar area is unfortunately suffering from many factories that let out their waste water into the irrigation canal and agricultural drains. Twenty five water samples were collected from five water resources to assess their heavy pollution. The determination of heavy metals (HV) water resources content conducted to compose the following increasing HV concentration sequences ; Drain Abu Qir (DA): Min (Cu)_Max (Zn), Canal Dbora Deufsho (CD): Min (Cu)_Max (Zn), Drain Dbora Abu Qir (DD): Min $(\mathrm{Cu}) \_\operatorname{Max}(\mathrm{Fe})$, Drain Kafr Dawar Deufsho (DK) : Min $(\mathrm{Cu}) \_M a x(\mathrm{Mn})$ and Drain Yarn and Fabric (DY) Min (Cu)_Max ( $\mathrm{Zn})$. Distribution patterns of HV concentration of water resources were (a) wide spread-distribution $(\mathrm{Cr}$, $\mathrm{Co}, \mathrm{Mn}),(\mathrm{b})$ moderately spread distribution pattern $(\mathrm{Cu}, \mathrm{Ni}, \mathrm{Pb})$, and (c) narrow spread distribution pattern $(\mathrm{Fe}, \mathrm{Cd}, \mathrm{Li}$ and $\mathrm{Zn}$ ). The association study conducted to classify the HV concentration into three groups; positively highly correlated $\mathrm{HV}$ : (Pb_Cd), (Pb_Co), (Pb_Cr), (Cd_Co), ( $\left.\mathrm{Zn} \_\mathrm{Fe}\right)$, (Cr_Co), (Ni_Co) and (Ni_Fe), negatively highly correlated HV: (Pb_Mn), (Cd_Mn), (Mn_Cu) and (Co_Li) and intermediate cases (non-significant positive and negative intercorrelation) that was represented by the other cases. The low values of contamination factor, of short term use (CfiST), showed that the majority of $\mathrm{HV}$ concentration, of the studied water resources was at safe use level. This certainly with exception of the cases of cadmium that classified the water resources DA and CD, and DD into polluted and risky levels, respectively. The high values of contamination factor, of long term use (CfiLT), indicated that the studied water resources were mainly contaminated by $\mathrm{Cd}$, Co and Cr heavy metals. Contrary, the low values of (CfiLT) of Zn, Fe, $\mathrm{Li}, \mathrm{Ni}, \mathrm{Pb}$ and $\mathrm{Cu}$, all studied water resources are safe. Contamination degree index (Cd) indicated the safe use at short term of water resources (DA), (CD) and (DD), and (DY) water resources were highly contaminated. According to (Cd) values, moderate risk is expected if we use the water resource (DK), even
\end{abstract}


in the short term. As for the long term use, all studied water resources were highly contaminated that they cannot be absolutely used in the long run.

\section{Keywords}

Heavy Metals, Water Pollution, Increasing Concentration Sequence, Contamination Factor, Kafr El-Dawar

\section{Introduction}

Heavy metals are elements having a specific gravity greater than four and their atomic weight ranges between 63.545 and $200.5 \mathrm{~g}$ [1]. Heavy metals pollution is very often caused by human activities [2] [3]. Industrial effluents discharged from various processing industries are the major sources of heavy metals pollution. These heavy metals reach to high concentrations and accumulate in dangerous quantity in different plant parts, and finally pose serious health hazard to human beings and animals [4]. The protection of water quality and sewage infrastructure did not increase along with HV population have created some earnest apprehensions for our environment [5] [6] [7] [8] [9]. [10] Applied multivariate statistical techniques, like principal component analysis (PCA), cluster analysis (CA) and factor analysis (FA) to identify the sources of heavy metals along a river basin.

HV water pollution is assessed by (a) referring to standard pollution tables of Environment Protection Agency (EPA) [11] and (b) applying of contamination indices, such as contamination index $\left(\mathrm{C}_{\mathrm{d}}\right)$ that may be called as contamination degree. The contamination index $\left(\mathrm{C}_{\mathrm{d}}\right)$ that summarizes the combined effects of several quality parameters considered harmful to domestic water [10] [12] [13] [14] [15]. The degree of contamination was used as a reference to estimate the extent of metal pollution. Contamination degree $\left(\mathrm{C}_{d}\right)$ has three categories; low $\left(C_{d}=\right.$ less $)$ medium $\left(C_{d}=1-3\right)$ and highly polluted $\left(C_{d}>3\right)[16]$.

A lot of researchers have focused on heavy metal pollution of all water resources around the world [17]-[23]. Generally, pollution indices are applied for water pollution estimation in the samples under consideration. The indexing approach of HV pollution assessment depends mainly on three indices; heavy metal pollution index (HPI), heavy metal evaluation index (HEI) and contamination degree $(\mathrm{Cd})[16]$.

The aims of this study are: (a) determine the resources and type of heavy metals (HV) water pollution, (b) assess the HV water pollution (in the cases of short and long uses), (c) define priority protecting water resources and (d) share the obtained results with the stakeholder agencies to start immediate pollution mitigation and conservation measures.

\section{Materials and Methods}

Kafr El-Dawar that was studied is a major industrial city and a municipality on 
the Nile Delta (Northern Egypt). Topographic-1:50,000 maps (Egyptian Survey Authority, Damanhour city, El-Bouheria Governorate) [24] were digitized, then the studied area was clipped (ARC-GIS Software, Version 9.3) [25]. In order to achieve the research objective, water samples were collected, at 24-12-2015, from twenty five locations. Water sampling was elaborated by stealstein $50 \mathrm{~cm}$-water sampler. These samples represented the water resources of Drain Abu Qir (DA), Canal Dbora Deufsho (CD), Drain Dbora Abu Qir (DD), Drain Kafr Dawar Deufsho (DK) and Drain Yarn and Fabric (DY), Table 1 and Figure 1. Five sites

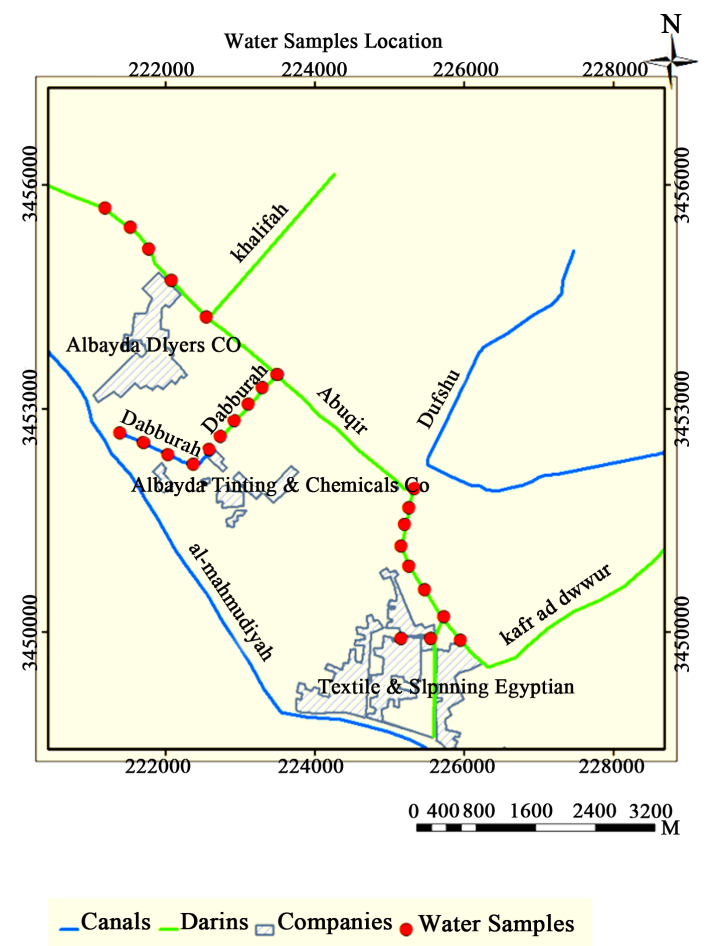

Figure 1. Location of water samples resources (Kafr El-Dawar region).

Table 1. Water samples coordinates.

\begin{tabular}{|c|c|c|c|c|c|c|c|}
\hline \multicolumn{2}{|c|}{ Drain/Canal } & \multicolumn{2}{|c|}{ Coordinates (UTM) } & \multicolumn{2}{|c|}{ Drain/Canal } & \multicolumn{2}{|c|}{ Coordinates (UTM) } \\
\hline Name & Sym $^{*}$ & $\mathrm{E}$ & $\mathbf{N}$ & Name & Sym. & $\mathrm{E}$ & $\mathbf{N}$ \\
\hline \multirow{6}{*}{ Drain Abu Qir } & \multirow{5}{*}{ DA } & 222,544 & $3,454,497$ & Drain & \multirow[b]{2}{*}{$\mathrm{DD}$} & 222,026 & $3,452,386$ \\
\hline & & 221,475 & $3,455,484$ & $\begin{array}{c}\text { Dbora } \\
\text { Abu Qir }\end{array}$ & & 222,370 & $3,452,249$ \\
\hline & & 221,527 & $3,455,432$ & \multirow{5}{*}{$\begin{array}{c}\text { Drain KAFR } \\
\text { DAWR } \\
\text { Deufsho }\end{array}$} & \multirow{5}{*}{ DK } & 225,467 & $3,454,498$ \\
\hline & & 221,767 & $3,455,140$ & & & 225,261 & $3,450,889$ \\
\hline & & 222,077 & $3,454,727$ & & & 225,158 & $3,451,147$ \\
\hline & \multirow{5}{*}{$\mathrm{CD}$} & 222,627 & $3,452,223$ & & & 225,261 & $3,451,663$ \\
\hline \multirow{4}{*}{$\begin{array}{c}\text { Canal Dbora } \\
\text { Deufsho }\end{array}$} & & 222,920 & $3,452,831$ & & & $2,253,330$ & $3,451,922$ \\
\hline & & 223,110 & $3,453,057$ & \multirow{6}{*}{$\begin{array}{c}\text { Drain } \\
\text { Yarn } \\
\text { and Fabric }\end{array}$} & \multirow{6}{*}{ DY } & 225,159 & $3,449,988$ \\
\hline & & 223,299 & $3,453,281$ & & & 225,553 & $3,449,908$ \\
\hline & & 223,488 & $3,453,453$ & & & 225,726 & $3,450,183$ \\
\hline \multirow{3}{*}{$\begin{array}{c}\text { Drain Dbora } \\
\text { Abu Qir }\end{array}$} & \multirow{3}{*}{$\mathrm{DD}$} & 222,573 & $3,452,200$ & & & 225,949 & $3,449,891$ \\
\hline & & 221,389 & $3,452,696$ & & & \multirow{2}{*}{225,467} & \multirow{2}{*}{$3,450,562$} \\
\hline & & 221,699 & $3,452,541$ & & & & \\
\hline
\end{tabular}

Sym*: symbol. 
were selected along each water resource. Polyethylene bottles were used for samples collection and it has been carefully washed at the laboratory before the sampling campaign. The collected samples were filtered (Whatman no. 42). Concentrations of heavy metals in water samples were determined by atomic absorption spectrophotometer (GCB-Avanta) using a specific lamp for particular metal. Average values of three replicates were taken for each determination and appropriate drift blank was taken before the analysis of samples [9].

Sources and type of water heavy metals pollution were assessed by three indicators (a) plotting of HV increasing concentration sequences (b) study HV distribution pattern (c) interpretation of the HV intercorrelation matrix. Descriptive statistics were calculated to assess HV data homogeneity that may indicate the HV resources. The whisker Plot box was drawn to present graphically HV pattern distribution. A Whisker Plot box gave information regarding the shape and variability of $\mathrm{HV}$ data set. It graphically presented $\mathrm{HV}$ distribution pattern [26].

$\mathrm{HV}$ water pollution was assessed by (a) referring to standard guidelines water pollution of EPA [11] and (b) applying Contamination degree index $\left(C_{d}\right)[16]$. A conventional scale was derived from recommended limits for constituents in reclaimed water for irrigation [11] to determine the classes of the heavy metal water pollution (Table 2). This conventional scale was based on standard maximum admissible concentration $\left(\mathrm{MAC}_{\mathrm{s}}\right)$ that is the upper permissible limits of cases of short and long term uses.

\section{Results and Discussion}

\section{(1) Sources and Type of Water Heavy Metals Pollution}

The sources and type of HV pollution were assessed by three indicators (a) establishment of $\mathrm{HV}$ increasing concentration sequence (b) study distribution pattern of $\mathrm{HV}$ water resources (c) interpretation of $\mathrm{HV}$ intercorrelation matrix.

Table 2. Conventional interpretative scale of heavy metals water pollution.

\begin{tabular}{ccccccccc}
\hline & \multicolumn{4}{c}{ Short Term Use $(\mu \mathrm{g} / \mathrm{L})$} & \multicolumn{4}{c}{ Long Term Use $(\mu \mathrm{g} / \mathrm{L})$} \\
\cline { 2 - 8 } & Ideal & Safe & Risky & Polluted & Ideal & Safe & Risky & Polluted \\
\hline $\mathrm{Cd}$ & $<2.5$ & $2.5-5$ & $5-50$ & $>50$ & $<0.5$ & $0.5-1$ & $1-10$ & $>10$ \\
$\mathrm{Co}$ & $<250$ & $250-500$ & $500-5000$ & $>5000$ & $<2.5$ & $2.5-5$ & $5-50$ & $>50$ \\
$\mathrm{Cr}$ & $<50$ & $50-100$ & $100-1000$ & $>1000$ & $<5$ & $5-10$ & $10-100$ & $>100$ \\
$\mathrm{Cu}$ & $<250$ & $250-500$ & $500-5000$ & $>5000$ & $<10$ & $10-20$ & $20-200$ & $>200$ \\
$\mathrm{Fe}$ & $<1000$ & $1000-2000$ & $2000-20,000$ & $>20,000$ & $<250$ & $250-500$ & $500-5000$ & $>5000$ \\
$\mathrm{Li}$ & $<125$ & $125-250$ & $250-2500$ & $>2500$ & $<125$ & $125-250$ & $250-2500$ & $>2500$ \\
$\mathrm{Mn}$ & $<500$ & $500-1000$ & $1000-10,000$ & $>10,000$ & $<10$ & $10-20$ & $20-200$ & $>200$ \\
$\mathrm{Ni}$ & $<100$ & $100-200$ & $200-2000$ & $>2000$ & $<10$ & $10-20$ & $20-200$ & $>200$ \\
$\mathrm{~Pb}$ & $<500$ & $500-1000$ & $1000-10,000$ & $>10,000$ & $<250$ & $250-500$ & $500-5000$ & $>5000$ \\
$\mathrm{Zn}$ & $<500$ & $500-1000$ & $1000-10,000$ & $>10,000$ & $<100$ & $100-200$ & $200-2000$ & $>2000$ \\
\hline
\end{tabular}

A conventional scale of pollution grade: Polluted: $>\mathrm{MAC}_{\mathrm{s}}$ Risky: $(10 \%) \mathrm{MAC}_{\mathrm{s}}-\mathrm{MAC}_{\mathrm{s}}$ Safe: $(5 \%) \mathrm{MAC}_{\mathrm{s}}-$ (10\%) $\mathrm{MAC}_{\mathrm{s}}$ Ideal: < (5\%) $\mathrm{MAC}_{\mathrm{s}}$. 
a) Plotting of increasing concentration sequence of heavy metals: Heavy metals in the content of water resources were determined (Table 3) and illustrated by Figure 2. The table showed that Fe had the highest concentration with an averaged value of $(98 \mu \mathrm{g} / \mathrm{L})$. Contrary, the lowest concentration was represented by $\mathrm{Cu}$ that had a mean of $(1.2 \mathrm{~g} / \mathrm{L})$. The figure showed that all increasing concentration sequences started by $\mathrm{Cu}$, and almost ended by $\mathrm{Zn}$. This may conduct to conclude that the studied water resources may have the same $\mathrm{Cu}-\mathrm{Zn}$ polluting source. Dissimilarly, the changeable location of $\mathrm{Pb}$, through the increasing concentration sequences, led to think that in the opposite conclusion.

b) Distribution Pattern of Heavy Metals in Water Resources: The descriptive statistics of water heavy metals content pointed out to great variations between the mean and median of heavy metals concentration in water (Table 4). This heterogeneity of HV concentration was confirmed by the high values of standard deviation.

These descriptive statistics, of heavy metals (HV) water resources content, led to select Wishker box plot-median to present (HV) distribution patterns. This type of whisker plot was preferred because of data heterogeneity (Figures 3(a)(c)). The figure indicated that the pollution of heavy metals water resources can be classified, according to their concentration homogeneity, into three distribution patterns:

- Wide spread-heterogeneous distribution pattern; Cr, Co and Mn (Figure $3(\mathrm{a}))$

- Moderate spread-moderately homogeneous distribution pattern; $\mathrm{Cu}, \mathrm{Ni}$ and $\mathrm{Pb}$ (Figure 3(b))

- Narrow spread-homogeneous distribution pattern; Cd, Fe, Li and $\mathrm{Zn}$ (Figure 3(c))

Table 3. Averaged concentration water heavy metal.

\begin{tabular}{ccccccccccc}
\hline \multirow{2}{*}{$\begin{array}{c}\text { Drain/Canal } \\
\text { Sym. }\end{array}$} & \multicolumn{10}{c}{ Heavy Metal Concentration $(\mu \mathrm{g} \backslash \mathrm{l})$} \\
\cline { 2 - 11 } & $\mathrm{Cd}$ & $\mathrm{Co}$ & $\mathrm{Cr}$ & $\mathrm{Cu}$ & $\mathrm{Fe}$ & $\mathrm{LI}$ & $\mathrm{Mn}$ & $\mathrm{Ni}$ & $\mathrm{Pb}$ & $\mathrm{Zn}$ \\
\hline $\mathrm{DA}$ & 10 & 11.41 & 26.25 & 1.42 & 8.26 & 3.3 & 41.7 & 13.8 & 29.5 & 43.8 \\
$\mathrm{CD}$ & 10 & 11.02 & 26.33 & 5.1 & 7.52 & 6.26 & 8.21 & 13.61 & 28.3 & 66.2 \\
DD & 9.84 & 11.3 & 25.3 & 4 & 98 & 5.95 & 55.7 & 14.03 & 18.2 & 96.8 \\
DK & 9.97 & 10.06 & 25.37 & 1.2 & 3.02 & 6.38 & 63.5 & 13.37 & 3.2 & 56.8 \\
DY & 9.35 & 10.17 & 25.6 & 3.3 & 2.97 & 6.3 & 7.6 & 13.12 & 19.7 & 54 \\
\hline
\end{tabular}

Table 4. Descriptive statistics of water heavy metals content.

\begin{tabular}{cccccccccccc}
\hline HV & Mean & Med & Min & Max & Std_Dev & HV & Mean & Med & Min & Max & Std_Dev \\
\hline Cd & 8.06 & 9.90 & 1.00 & 10.00 & 3.96 & Li & 5.66 & 6.30 & 3.30 & 6.40 & 1.33 \\
Cr & 25.70 & 25.40 & 25.20 & 26.30 & 0.55 & Mn & 35.76 & 43.80 & 7.60 & 63.50 & 26.38 \\
Co & 10.80 & 11.00 & 10.10 & 11.40 & 0.61 & Ni & 13.58 & 13.60 & 13.10 & 14.00 & 0.35 \\
$\mathrm{Cu}$ & 3.00 & 3.30 & 1.20 & 5.10 & 1.68 & Pb & 19.78 & 19.70 & 3.20 & 29.50 & 10.54 \\
$\mathrm{Fe}$ & 23.96 & 7.50 & 3.00 & 98.00 & 41.46 & ZN & 63.52 & 56.80 & 43.80 & 96.80 & 20.25 \\
\hline
\end{tabular}



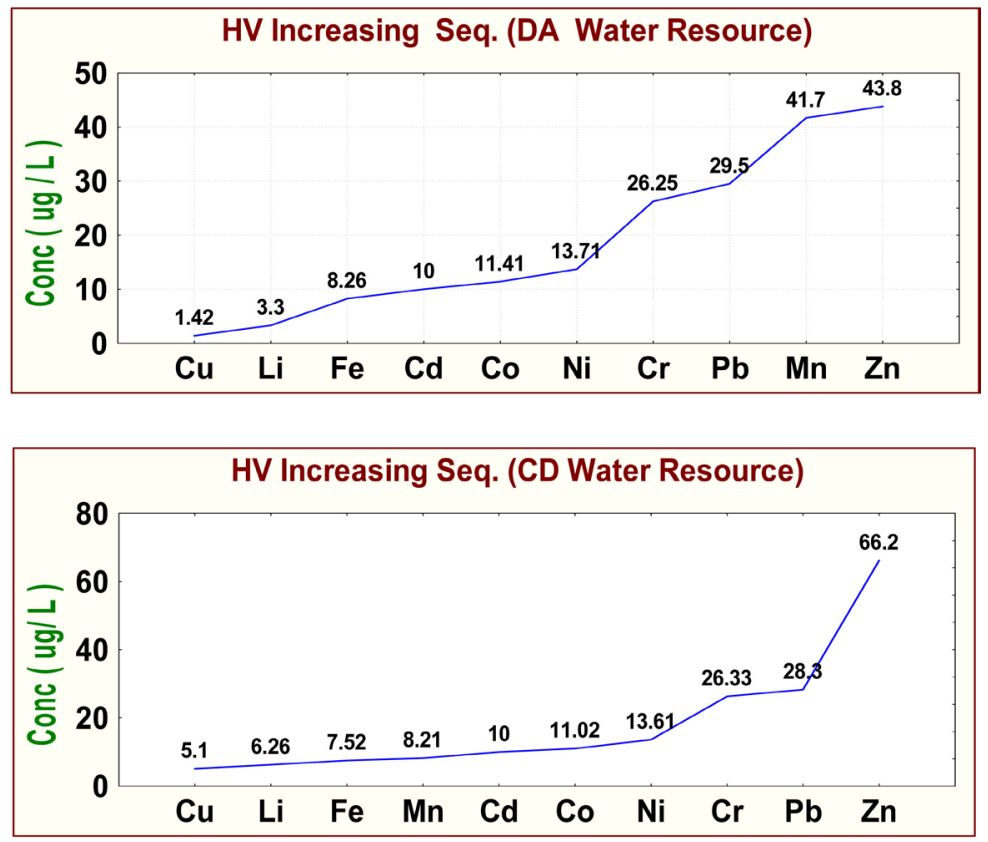

(a)
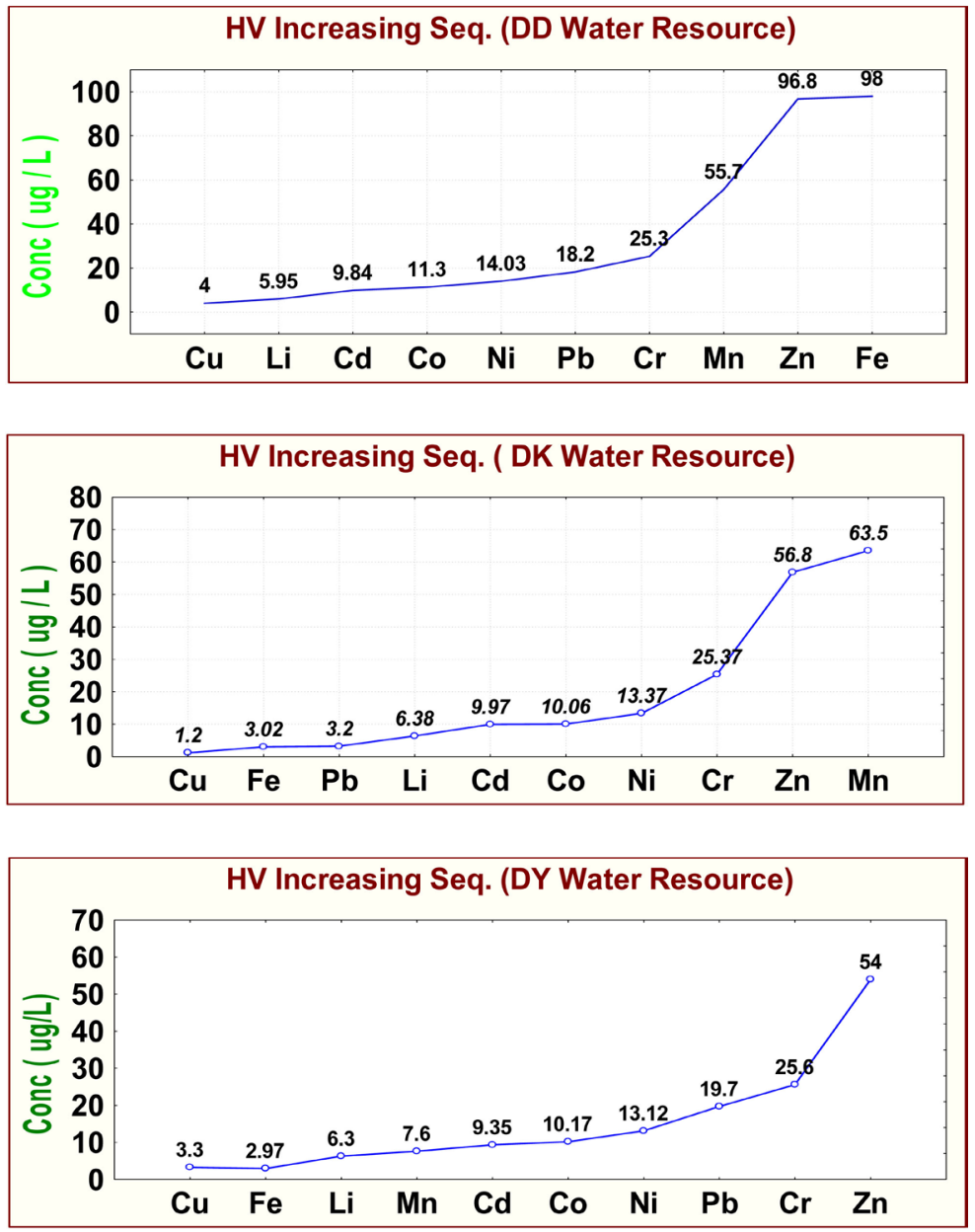

(b)

Figure 2. (a) Increasing sequence of heavy metals of water resources DA and CD; (b) increasing sequence of heavy metals of water resources DD, DK and DY. 

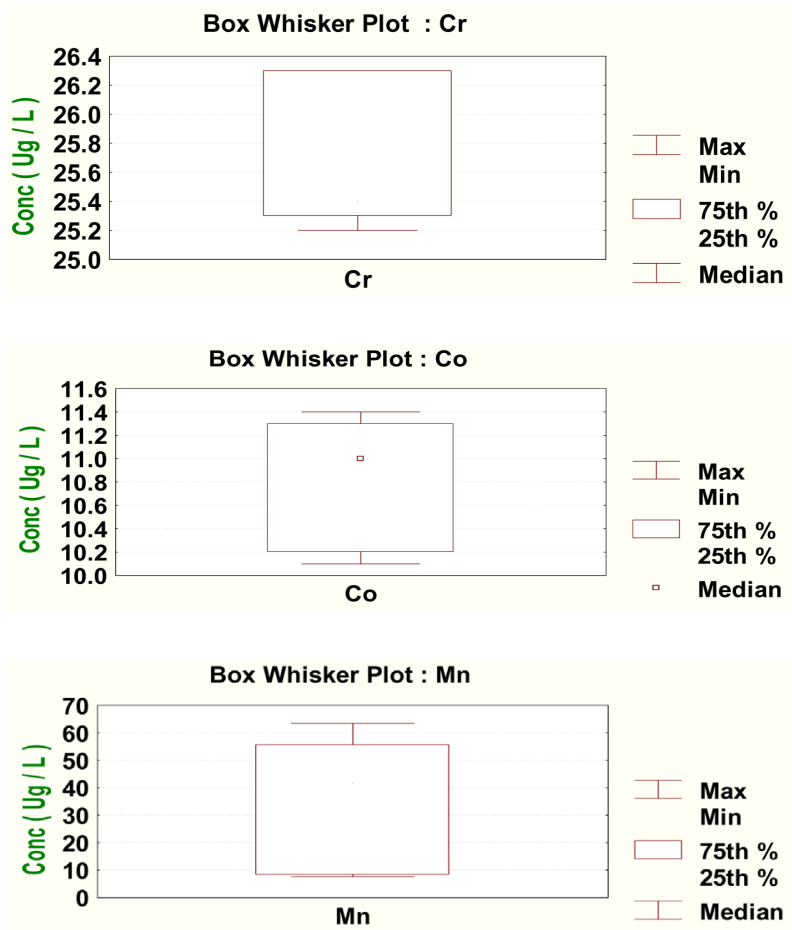

(a)
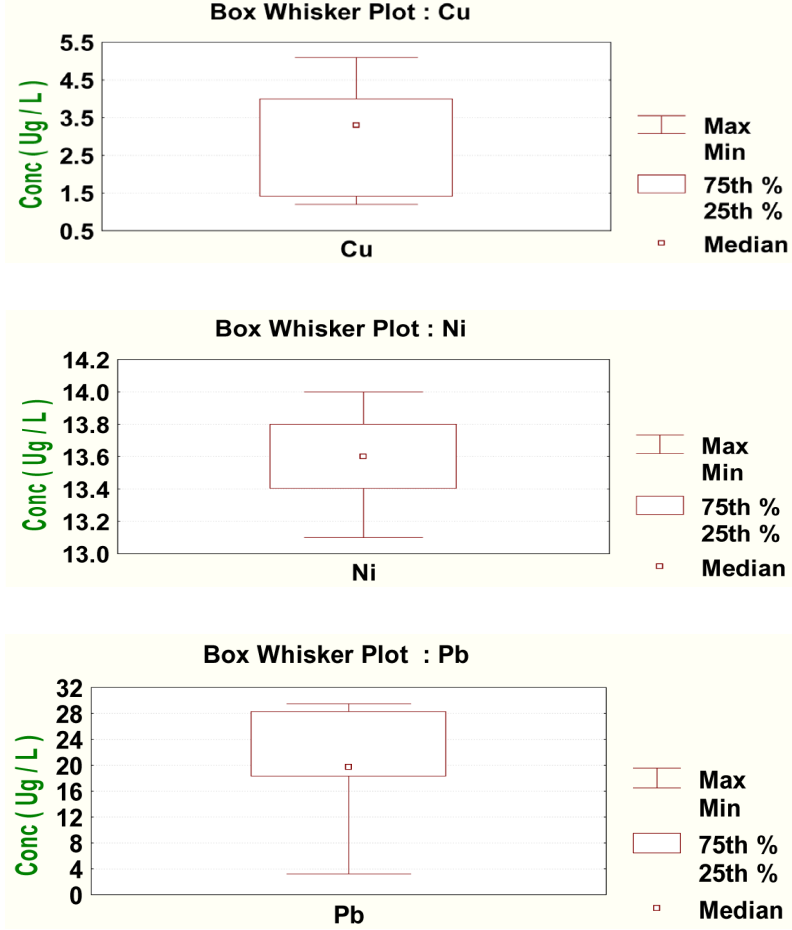

(b)

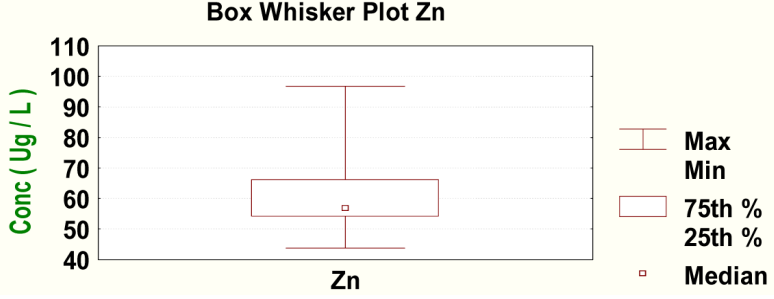



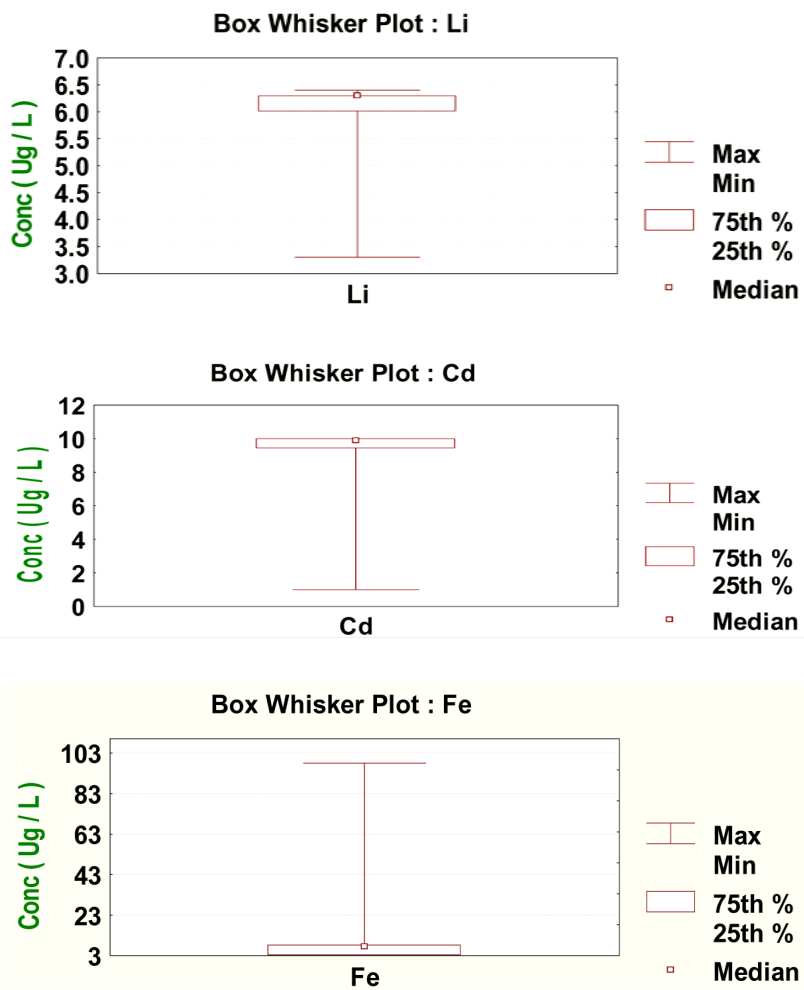

(c)

Figure 3. (a) Wide spread-distribution pattern ( $\mathrm{Cr}, \mathrm{Co}, \mathrm{Mn})$; (b) distribution pattern: moderatly spread pattern $(\mathrm{Cu}, \mathrm{Ni}, \mathrm{Pb})$; (c) distribution pattern: narrow spread pattern (Fe,Cd, $\mathrm{Li}$ and $\mathrm{Zn}$ ).

c) HV intercorrelation matrix: The HV intercorrelation matrix was calculated (Table 5) to assess their associations. These associations conducted to classify the HV into three groups;

- Positively highly correlated HV: (Zn_Fe), (Pb_Cd), (Pb_Co), (Pb_Cr), (Cd_Co), (Ni_Cr) and (Ni_Fe)

- Negatively highly correlated HV: (Co_Li), (Cu_Mn) (Pb_Mn) and (Cd_Mn)

- Intermediate cases (moderate positive and negative correlation)

The positively highly intercorrelated of $\mathrm{Zn}, \mathrm{Fe}, \mathrm{Pb}, \mathrm{Cd}$, $\mathrm{Co}$ and $\mathrm{Cr}$ led to conclude that the studied water resources have been received these five heavy metals from the same pollution source. Contrary, the negatively highly intercorrelated $\mathrm{HV}$; (Pb_Mn), (Cd_Mn), (Mn_Cu) and (Co_Li) might be a tool to assume that these heavy metals coming from different pollution resources. The intermediate cases of low positive and negative correlation coefficients indicated multiple pollution resources.

(2) Assessment of heavy metals pollution (cases of short and long term use)

The heavy metals pollution in water resources, of the cases of short and long term uses, was assessed by basing on two approaches (i) the annotative conventional scale of contamination factor $\left(\mathrm{C}_{\mathrm{i}}\right)$ and (ii) contamination degree index $\left(\mathrm{C}_{\mathrm{d}}\right)$. 
Table 5. The HV correlation matrix.

\begin{tabular}{ccccccccccc}
\hline $\mathrm{HV}$ & $\mathrm{Cd}$ & $\mathrm{Co}$ & $\mathrm{Cr}$ & $\mathrm{Cu}$ & $\mathrm{Fe}$ & $\mathrm{Li}$ & $\mathrm{Mn}$ & $\mathrm{Ni}$ & $\mathrm{Pb}$ & $\mathrm{Zn}$ \\
\hline $\mathrm{Cd}$ & 1.00 & & & & & & & & & \\
$\mathrm{Co}$ & 0.68 & 1.00 & & & & & & & & \\
$\mathrm{Cr}$ & 0.35 & 0.58 & 1.00 & & & & & & & \\
$\mathrm{Cu}$ & 0.60 & 0.25 & 0.08 & 1.00 & & & & & & \\
$\mathrm{Fe}$ & 0.30 & 0.51 & -0.35 & 0.34 & 1.00 & & & & & \\
$\mathrm{Li}$ & -0.34 & -0.62 & -0.58 & 0.48 & 0.10 & 1.00 & & & & \\
$\mathrm{Mn}$ & -0.56 & 0.10 & -0.24 & -0.62 & 0.41 & -0.20 & 1.00 & & & \\
$\mathrm{Ni}$ & 0.34 & 0.89 & 0.35 & 0.12 & 0.71 & -0.43 & 0.49 & 1.00 & & \\
$\mathrm{~Pb}$ & 0.90 & 0.71 & 0.71 & 0.43 & -0.03 & -0.54 & -0.58 & 0.32 & 1.00 & \\
$\mathrm{Zn}$ & 0.20 & 0.32 & -0.37 & 0.59 & 0.91 & 0.45 & 0.24 & 0.55 & -0.13 & 1.00 \\
\hline
\end{tabular}

(2-1) Assessment of Heavy Metals Water Pollution by contamination factor $\left(C_{i}\right)$

An interpretative scale of contamination factor $\left(\mathrm{C}_{\mathrm{fi}}\right.$ was derived by basing on the guidelines of the safe limits of Brraich and Jangu (2015) and EPA (2004). Scale's thresholds were calculated as follows:

Contamination factor $\left(\mathrm{C}_{\mathrm{fi}}\right)=\left(\mathrm{C}_{\mathrm{Ai}}\right)$ analytical conc. $/\left(\mathrm{C}_{\mathrm{Ni}}\right)$ Permissible Conc.-1

By designation: $(\mathrm{ST})=$ short term use, and $(\mathrm{LT})=$ long term use

Thus, $\mathrm{C}_{\mathrm{fiST}}$ and $\mathrm{C}_{\text {fiLT }}$ refer to the contamination factor of the cases of short and long term use, respectively (Table 6).

The contamination factor of the studied water resources was calculated to assess individually the contamination degree of each heavy metal (Table 7). The application of the conventional interpretative scale of heavy metals water pollution referred that the different grade pollution of each heavy metals. The table pointed out that the values of contamination factor, of short term use, $\left(\mathrm{C}_{\mathrm{fST}}\right)$ were generally valued to lay the studied water resources at safe use level (Table 7 (a)). This conclusion excluded the cases of cadmium that classified the water resources DA, CD, and DD into polluted and risky levels, respectively.

The values of contamination factor, of long term use, $\left(\mathrm{C}_{\mathrm{fiLT}}\right)$ designated the level of water heavy metals pollution (Table $7(b)$ ). The table showed that the studied water resources were mainly contaminated by $\mathrm{Cd}$, Co and $\mathrm{Cr}$ heavy metals. Cobalt and $\mathrm{Cr}$ heavy metals grouped all studied water resources in the polluted level. In addition, the table showed that the water resources were also highly contaminated by Cd heavy metal that they were classified as Cd-polluted (DA, CD, DD, DY) and Cd-risky (DK). Contamination factor $\left(\mathrm{C}_{\text {fiLT }}\right)$ of Mn was high to be classified DD as polluted water resource. According to the values of $\left(\mathrm{C}_{\text {fiLT }}\right)$ of $\mathrm{Zn}, \mathrm{Fe}, \mathrm{Li}, \mathrm{Ni}, \mathrm{Pb}$ and $\mathrm{Cu}$, all studied water resources are safe to use at long term. The table showed that the Co concentration of all studied water resources, occupied the polluted class. Meanwhile, $\mathrm{Zn}$ concentration of the water resource (DK) represented polluted class in the long term use. Ideal and safe 
Table 6. Interpretative scale of contamination factor $\left(\mathrm{C}_{\mathrm{fi}}\right)$.

\begin{tabular}{|c|c|c|c|c|}
\hline \multirow{2}{*}{$\mathbf{N}$} & \multicolumn{2}{|c|}{ Case } & \multirow{2}{*}{$\begin{array}{c}\mathrm{C}_{\mathrm{fiST}} \\
\text { OR } \\
\mathrm{C}_{\text {fiLT }}\end{array}$} & \multirow{2}{*}{$\begin{array}{c}\text { Contamination } \\
\text { Level }\end{array}$} \\
\hline & Short term use & Long term use & & \\
\hline 1 & $\left(\mathrm{C}_{\mathrm{Ai}}\right)$ less than $1 / 2\left(\mathrm{C}_{\mathrm{NiST}}\right)$ & $\left(\mathrm{C}_{\mathrm{Ai}}\right)$ less than $1 / 2\left(\mathrm{C}_{\mathrm{NiLT}}\right)$ & $<-0.5$ & Safe \\
\hline 2 & $\left(\mathrm{C}_{\mathrm{Ai}}\right)=1 / 2(\mathrm{PC}) \mathrm{OR}=\left(\mathrm{C}_{\mathrm{NiST}}\right)$ & $\left(\mathrm{C}_{\mathrm{Ai}}\right)=1 / 2\left(\mathrm{C}_{\mathrm{NiLT}}\right) \mathrm{OR}=\left(\mathrm{C}_{\mathrm{NiLT}}\right)$ & $\geq-0.5-<1$ & Risky \\
\hline 3 & $\left(\mathrm{C}_{\mathrm{Ai}}\right)>\left(\mathrm{C}_{\mathrm{NiST}}\right)$ & $\left(\mathrm{C}_{\mathrm{Ai}}\right)>\left(\mathrm{C}_{\mathrm{NiLT}}\right)$ & $\geq 1$ & Polluted \\
\hline
\end{tabular}

Table 7. (a) Grades of heavy metal pollution water (case of short term use) basing on contamination factor $\left(\mathrm{C}_{\mathrm{fiST}}\right)$; (b) Grades of heavy metal pollution water (case of long term use) basing on contamination factor (CfiLT).

(a)

\begin{tabular}{ccccccccccc}
\hline \multirow{2}{*}{$\begin{array}{c}\text { Drain/Canal } \\
\text { Sym. }\end{array}$} & \multicolumn{8}{c}{ Contamination Factor $\left(\mathrm{C}_{\mathrm{fi}}\right)$ of Heavy Metal Pollution Water } \\
\cline { 2 - 10 } & Cd & Co & Cr & Cu & Fe & Li & Mn & Ni & Pb & Zn \\
\hline \multirow{2}{*}{ DA } & 1 & -0.98 & -0.74 & -1.00 & -1.00 & -0.99 & -0.96 & -0.93 & -0.97 & -0.96 \\
& Polluted & Safe & Safe & Safe & Safe & Safe & Safe & Safe & Safe & Safe \\
CD & 1 & -0.98 & -0.74 & -0.99 & -1.00 & -0.97 & -0.99 & -0.93 & -0.97 & -0.93 \\
& Polluted & Safe & Safe & Safe & Safe & Safe & Safe & Safe & Safe & Safe \\
\multirow{2}{*}{ DD } & 0.98 & -0.98 & -0.75 & -0.99 & -0.95 & -0.98 & -0.94 & -0.93 & -0.98 & -0.90 \\
& Risky & Safe & Safe & Safe & Safe & Safe & Safe & Safe & Safe & Safe \\
DK & -0.88 & -0.98 & -0.75 & -1.00 & -1.00 & -0.97 & -0.97 & -0.93 & -1.00 & -0.94 \\
& Safe & Safe & Safe & Safe & Safe & Safe & Safe & Safe & Safe & Safe \\
\multirow{2}{*}{ DY } & -0.88 & -0.98 & -0.75 & -0.99 & -1.00 & -0.95 & -0.99 & -0.97 & -0.98 & 0.95 \\
& Safe & Safe & Safe & Safe & Safe & Safe & Safe & Safe & Safe & Risky \\
\hline
\end{tabular}

(b)

\begin{tabular}{|c|c|c|c|c|c|c|c|c|c|c|}
\hline \multirow{2}{*}{$\begin{array}{c}\text { Drain/Canal } \\
\text { Sym. }\end{array}$} & \multicolumn{10}{|c|}{ Contamination Factor $\left(\mathrm{C}_{\mathrm{fiLT}}\right)$ of Heavy Metal Pollution Water } \\
\hline & $\mathrm{Cd}$ & Co & $\mathrm{Cr}$ & $\mathrm{Cu}$ & $\mathrm{Fe}$ & $\mathrm{Li}$ & Mn & $\mathrm{Ni}$ & $\mathrm{Pb}$ & $\mathrm{Zn}$ \\
\hline \multirow{2}{*}{$\mathrm{DA}$} & 9 & 1.2 & 1.63 & -0.75 & -0.99 & -0.97 & -0.59 & -0.32 & -0.94 & -0.67 \\
\hline & Polluted & Polluted & Polluted & Safe & Safe & Safe & Safe & Risky & Safe & Safe \\
\hline \multirow{2}{*}{$\mathrm{CD}$} & 9 & 1.2 & 1.63 & -0.75 & -0.99 & -0.97 & -0.59 & -0.32 & -0.94 & -0.67 \\
\hline & Polluted & Polluted & Polluted & Safe & Safe & Safe & Safe & Risky & Safe & Safe \\
\hline \multirow{2}{*}{ DD } & 8.9 & 1.26 & 1.53 & -0.8 & -0.8 & -0.98 & 1.79 & -0.3 & -0.96 & -0.52 \\
\hline & Polluted & Polluted & Polluted & Safe & Safe & Safe & Polluted & Safe & Safe & Safe \\
\hline \multirow{2}{*}{ DK } & 0 & 1.02 & 1.54 & -0.94 & -0.99 & -0.97 & -0.83 & -0.33 & -0.99 & -0.72 \\
\hline & Risky & Polluted & Polluted & Safe & Safe & Safe & Safe & Safe & Safe & Safe \\
\hline \multirow{2}{*}{ DY } & 8.4 & 1.04 & 1.52 & -0.84 & -0.99 & -0.95 & -0.62 & -0.69 & -0.96 & -0.73 \\
\hline & Polluted & Polluted & Polluted & Safe & Safe & Safe & Safe & Safe & Safe & Safe \\
\hline
\end{tabular}

classes dominated the cases, meanwhile the risky pollution class was only found in a few cases. The contamination factor of cadmium $\left(\mathrm{C}_{\mathrm{fCd}}\right)$ had generally the highest values to refer that cadmium is the more effective pollutant. 
(2-2) Assessment of heavy metals pollution (cases of short and long term use) by the contamination degree index $\left(C_{d}\right)$

The contamination degree index $\left(\mathrm{C}_{\mathrm{d}}\right)$ summarizes the combined effects of several heavy metals that are considered harmful to irrigation water [12]. This index is calculated from the formula below:

$$
C_{d}=\sum_{i=1}^{n} C f I
$$

where

$$
C f i=\left(\frac{C A i}{C N i}\right)-1
$$

where $\mathrm{Cfi}$, CAi and $\mathrm{CNi}$ represent contamination factor, analytical value and the upper allowable concentration of the ith component, respectively ( $\mathrm{N}$ denotes the normative value). The index of the contamination degree $\left(\mathrm{C}_{\mathrm{d}}\right)$ was calculated to assess the water pollution by all studied heavy metals (Table 8). In the cases of short use, the $\left(C_{d}\right)$ values ranged from -7.49 (water resource of DA) to 7.51 (water resource of $C D)$. As for the cases of long use, the $\left(C_{d}\right)$ values extended from 5.49 (water resource of DY) to 33.20 (water resource of DK). The degree of contamination $\left(\mathrm{C}_{\mathrm{d}}\right)$ was used as reference to estimate the extent of heavy metal pollution [27], Table 9).

The table showed that the contamination degree index $\left(\mathrm{C}_{\mathrm{d}}\right)$ of water resources (DY), (DD) and (DA) had the negative values of $-5.67,-7.26$ and -7.49 , respectively, indicating water safety use of the term of short run. $\mathrm{C}_{\mathrm{d}}$ of water resources (CD) had the value of 7.51 to classify (Cd) water resources were highly contaminated at short run use. Moderate risk is expected if we use the water resource (DK), even in the short term. As for the long term use, all studied water re-

Table 8. Contamination degree index of studied water resources.

\begin{tabular}{cccccc}
\hline & & \multicolumn{4}{c}{ Contamination Index $\left(\mathrm{C}_{\mathrm{d}}\right)$} \\
\cline { 3 - 6 } $\mathrm{N}$ & Canal/Drain & \multicolumn{2}{c}{ Short Use } & \multicolumn{2}{c}{ Long Use } \\
\cline { 3 - 6 } & & $\left(\mathrm{C}_{\mathrm{d}}\right)$ & $\left(\mathrm{C}_{\mathrm{d}}\right)$ Class & $\left(\mathrm{C}_{\mathrm{d}}\right)$ & $\left(\mathrm{C}_{\mathrm{d}}\right)$ Class \\
\hline 1 & DA & -7.49 & Safe & 8.06 & High \\
2 & CD & 7.51 & High & 6.61 & High \\
3 & DD & -7.26 & Safe & 9.75 & High \\
4 & DK & 2.80 & Medium & 33.20 & High \\
5 & DY & -5.67 & Safe & 5.49 & High \\
\hline
\end{tabular}

Table 9. Interpretative scale of contamination degree index $\left(C_{d}\right)$.

\begin{tabular}{cccc}
\hline \multirow{2}{*}{$\mathbf{N}$} & Contamination Degree & \multicolumn{2}{c}{ Contamination Index $\left(\mathrm{C}_{\mathrm{d}}\right)$} \\
\cline { 3 - 4 } & & Short Use & Long Use \\
\hline 1 & Safe & $<0.0$ & $<0.0$ \\
2 & Low & $\leq 1$ & $\leq 0.5$ \\
3 & Medium & $>1-<3$ & $>0.5-<1.5$ \\
4 & High & $\leq 3$ & $\leq 1.5$ \\
\hline
\end{tabular}


sources were high contaminated that they cannot be absolutely used in the long run (Table 8).

\section{Conclusions}

The current research led to conclude that the sources and type of water heavy metals pollution may be determined by three indicators (a) plotting of HV increasing concentration sequence (b) study distribution pattern of HV water resources (c) interpretation of the HV intercorrelation matrix. This conclusion supports enhance the capability of environmental monitoring and supervision of HV water pollution

The application of 2004-EPA water guidelines classifies HV water pollution into two categories; safe and polluted classes. This is due to the fact that EPA water guidelines are only based on the upper permissible limits of cases of short $\left(\mathrm{MAC}_{\mathrm{ss}}\right)$ and long term $\left(\mathrm{MAC}_{\mathrm{sl}}\right)$ uses. The study applied a conventional and innovative scale to more accurately determine the classes of the heavy metal water pollution. Where the innovative scale introduced two new classes; ideal and risky. Thus, this more accurate classification that includes four categories of $\mathrm{HV}$ water pollution (ideal, safe, risky, polluted) enables to define the priority protection water resources.

Ideal and safe waters of short use change to risky or polluted for the cases of long use. The assessment of $\mathrm{HV}$ water pollution becomes more accurate if it is estimated contamination degree $\left(\mathrm{C}_{\mathrm{d}}\right)$ than contamination factor $\left(\mathrm{C}_{\mathrm{f}}\right)$. This due to fact that the contamination degree index $\left(C_{d}\right)$ usually summarizes the combined effects of several heavy metals considered harmful to irrigation water.

\section{References}

[1] Connel, B.S., Cox, M. and Singer, I. (1984) Nickel and Chromium. In: Brunner, F. and Coburn, J.W., Eds., Disorders of Minerals Metabolism, Academic Press, New York, 472-532.

[2] Mwegoha, W.J.S. and Kihampa, C. (2010) Heavy Metal Contamination in Agricultural Soils and Water in Dar es Salaam City, Tanzania. African Journal of Environmental Science and Technology, 4, 763-769.

[3] Wikipedia (2016) Toxic Heavy Metal. https://en.wikipedia.org/wiki/Toxic_heavy_metal

[4] Ray, M. (1990) Accumulation of Heavy Metals in Plants Grown in Industrial Areas. Indian Biologists, XXII, 33-38.

[5] Sundaray, S.K., Panda, U.C., Nayak, B.B. and Bhatta, D. (2006) Multivariate Statistical Techniques for the Evaluation of Spatial and Temporal Variation in Water Quality of Mahanadi River-Estuarine System (India) A Case Study. Environmental Geochemistry and Health, 28, 317-330. https://doi.org/10.1007/s10653-005-9001-5

[6] Karbassi, A.R., Nouri, J. and Ayaz, G.O. (2007) Flocculation of Trace Metals during Mixing of Talar River Water with Caspian Seawater. International Journal of Environmental Research, 1, 66-73.

[7] Akoto, O., Bruce, T.N. and Darko, G. (2008) Heavy Metals Pollution Profiles in Streams Serving the Owabi Reservoir. African Journal of Environmental Science and Technology, 2, 354-359. 
[8] Ahmad, M.K., Islam, S., Rahman, S., Haque, M.R. and Islam, M.M. (2010) Heavy Metals in Water, Sediment and Some Fishes of Buriganga River, Bangladesh. International Journal of Environmental Research, 4, 321-332.

[9] Reza, R. and Singh, G. (2010) Heavy Metal Contamination and Its Indexing Approach for River Water. International Journal of Environmental Science and Technology, 7, 785-792. https://doi.org/10.1007/BF03326187

[10] Manoj, K., Padhy P.K. and Chaudhury, S. (2012) Study of Heavy Metal Contamination of the River Water through Index Analysis. Approach and Bull. Env. Pharmacol. Life Sci., 1, 7-15.

[11] EPA (2004) Environment Protection Agency, Guidelines for Water Reuse, EPAUSA/625/R-04/108; Table 4-13, 167-170. http://www.lacsd.org/civica/filebank/blobdload.asp?BlobID $=2184$

[12] Backman, B., Bodis, D., Lahermo, P. and Rapant, S. (1997) Application of a Groundwater Contamination Index in Finland and Slovakia. Environmental Geology, 36, 55-64. https://doi.org/10.1007/s002540050320

[13] Amadi, A.N., Olasehinde, P.I., Okosun, E.A. and Yisa, J. (2010) Assessment of the Water Quality Index of Otamiri and Oramiriukwa Rivers. Physics International, 1, 116-123.

[14] Aweng, E.R., Karimah, M. and Suhaimi, O. (2011) Heavy Metals Concentration of Irrigation Water, Soils and Fruit Vegetables in Kota Bharu Area, Kelantan, Malaysia. Journal of Applied Sciences in Environmental Sanitation, 6, 463-470.

[15] Nasrabadi, T. (2015) An Index Approaches to Metallic Pollution in River Waters. International Journal of Environmental Research, 9, 385-394.

[16] Brraich, S.O. and Jangu, S. (2015) Evaluation of Water Quality Pollution Indices for Heavy Metal Contamination in the Water of Harike Wetland (Ramsar Site) India. International Journal of Scientific and Research, 5, 2250-3153.

[17] Prasad, B. and Bose, J. (2001) Evaluation of the Heavy Metal Pollution Index for Surface and Spring Water near a Limestone Mining Area of the Lower Himalayas. Environmental Geology Journal, 41, 183-188. https://doi.org/10.1007/s002540100380

[18] Edet, A.E. and Offiong, O.E. (2002) Evaluation of Water Quality Pollution Indices for Heavy Metal Contamination Monitoring. A Study Case from AkpabuyoOdukpani Area, Lower Cross River Basin (Southeastern Nigeria). Geomicrobiology Journal, 57, 295-304. https://doi.org/10.1023/b:gejo.0000007250.92458.de

[19] Bird, G., Brewer, P.A., Macklin, M.G., Serban, M., Balteanu, D. and Driga, B. (2005) Heavy Metal Contamination in the Aries River Catchment, Western Romania: Implications for Development of the RosiaMontana Gold Deposit. Journal of Geochemical Exploration, 86, 26-48. https://doi.org/10.1016/j.gexplo.2005.02.002

[20] Nabi, B.G.R., Karbassi, A.R., Nasrabadi, T. and Hoveidi, H. (2007) Influence of Copper Mine on Surface Water Quality. International Journal of Environmental Research, 4, 85-91.

[21] Wang, X., Lu, Y., Han, J., He, G. and Wang, T. (2007) Identification of Anthropogenic Influences on Water Quality of Rivers in Taihu Watershed. Journal of Environmental Sciences, 19, 475-481. https://doi.org/10.1016/S1001-0742(07)60080-1

[22] Zhang, Y., Guo, F., Meng, W. and Wang, X.Q. (2009) Water Quality Assessment and Source Identification of Daliao River Basin Using Multivariate Statistical Methods. Environmental Monitoring and Assessment, 152, 105-121. https://doi.org/10.1007/s10661-008-0300-Z

[23] Nasrabadi, T., NabiBidhendi, G.R., Karbassi, A. R., Hoveidi, H., Nasrabadi, I., Pe- 
zeshk, H. and Rashidinejad, F. (2009) Influence of Sungun Coppermine on Groundwater Quality, NW, Iran. Environmental Geology, 58, 693-700. https://doi.org/10.1007/s00254-008-1543-2

[24] Egyptian Survey Authority, Damanhour City, El-Bouheria Governorate (1998) 1:50000 Scaled-Topographic Maps.

[25] ARC-GIS Software, Version: 9.3 (2014). http://www.arcgis.com/home/gallery.html

[26] Rumsey, D.J. (2016) What a Boxplot Can Tell You about a Statistical Data Set. http://www.dummies.com/how-to/content/what-a-boxplot-can-tell-you-about-a-st atistical-da.html

[27] Al-Ami, M.Y., Al-Nakib, S.M., Ritha, N.M., Nouri, A.M. and Al-Assina, A. (1987) Water Quality Index Applied to the Classification and Zoning of Al-Jaysh Canal, Bagdad, Iraq. Journal Environmental Science and Health, 22, 305-319.

Submit or recommend next manuscript to SCIRP and we will provide best service for you:

Accepting pre-submission inquiries through Email, Facebook, LinkedIn, Twitter, etc. A wide selection of journals (inclusive of 9 subjects, more than 200 journals)

Providing 24-hour high-quality service

User-friendly online submission system

Fair and swift peer-review system

Efficient typesetting and proofreading procedure

Display of the result of downloads and visits, as well as the number of cited articles

Maximum dissemination of your research work

Submit your manuscript at: http://papersubmission.scirp.org/

Or contactnr@scirp.org 